\title{
Pleomorphic adenoma of the minor salivary gland of the cheek
}

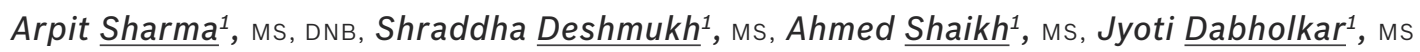

ABSTRACT Pleomorphic adenoma is the most common tumour of the salivary gland. While the majority arises from the parotid gland, only a small percentage arises from the minor salivary glands. The cheek, however, is a rarely affected site with respect to pleomorphic adenomas of the minor salivary glands. Herein, we report a case of pleomorphic adenoma of the cheek, which presented with intraoral swelling, and conclude that complete surgical excision can be a curative treatment for this benign tumour.

Keywords: cheek, gland, minor, pleomorphic, salivary

\section{INTRODUCTION}

Pleomorphic adenoma is a benign tumour of the salivary glands arising from myoepithelial and intercalated duct cells, and is the most common tumour of the salivary gland. $70 \%$ of these tumours occur in the parotid gland, and around $22 \%$ in the minor salivary glands. ${ }^{(1)}$ This report describes a case of pleomorphic adenoma arising in the cheek, which underwent therapeutic wide local excision with wide margins. Although pleomorphic adenomas arising from the minor salivary glands rarely affect the cheeks, the condition should still be considered in the differential diagnosis of cheek masses.

\section{CASE REPORT}

A 40-year-old Indian man presented with a slow-growing, painless swelling in the left cheek of 20 years' duration. Clinical examination revealed a $4 \mathrm{~cm} \times 4 \mathrm{~cm}$ firm, mobile mass in the left cheek, $2 \mathrm{~cm}$ distal to the angle of the mouth. Computed tomography revealed a homogeneously enhancing mass, measuring $3 \mathrm{~cm}$, in the left cheek, extending anteriorly to the anterior wall of the left maxillary sinus, with mild scalloping of the underlying bone. Fine-needle aspiration cytology from the swelling revealed features of pleomorphic adenoma.

Under local anaesthesia, a horizontal intraoral incision was made on the buccal mucosa. While performing the incision, care was taken to avoid injury to the parotid duct opening located on the surface of the buccal mucosa, opposite the upper second molar tooth. The tumour was resected from the surrounding tissue (Fig. 1). As the mass did not involve the facial muscles or the subcutaneous tissue of the cheek, wide local excision with satisfactory margins was performed. The resultant defect in the buccal mucosa was closed primarily by simple mucosal approximation. On gross examination, the tumour was observed to be firm, bosselated and ovoid in shape. The final histopathological result was suggestive of pleomorphic adenoma.

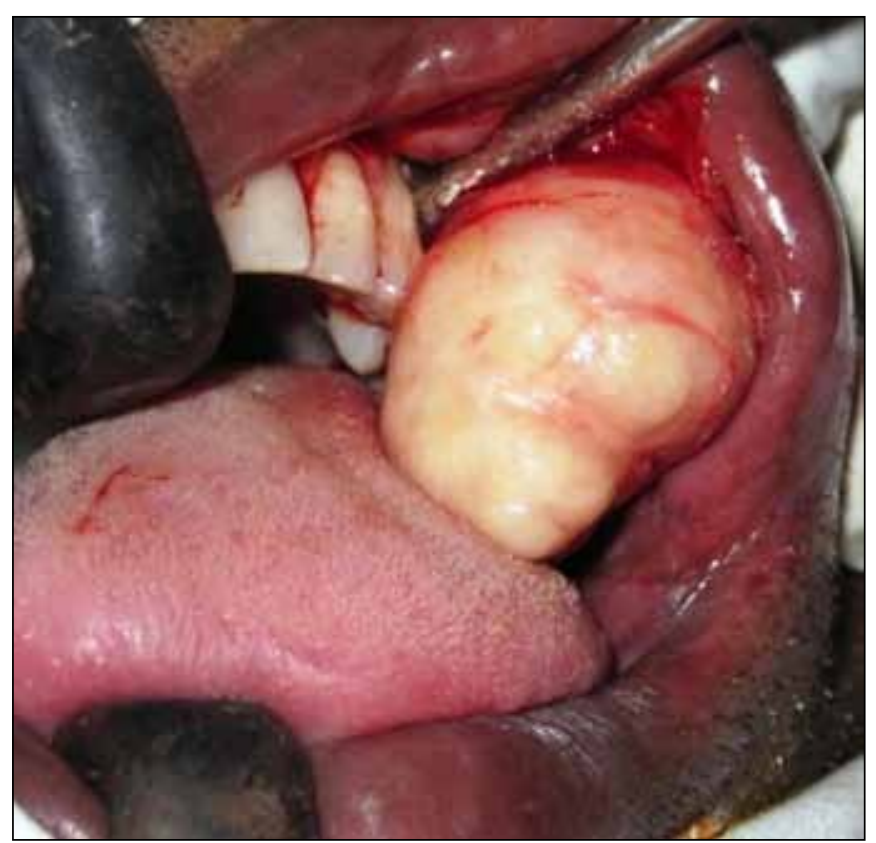

Fig. 1 Intraoperative photograph shows pleomorphic adenoma of the cheek.

\section{DISCUSSION}

Neoplasms of the salivary glands account for less than $1 \%$ of all tumours, and $3 \%-5 \%$ of all head and neck tumours. ${ }^{(1)}$ Around $70 \%$ of these tumours occur in the parotid gland, $10 \%$ in the submandibular gland and the remainder in the minor salivary glands. ${ }^{(2)}$ Pleomorphic adenoma is the most common tumour of the major and minor salivary glands. ${ }^{(1)}$ Among the intraoral sites, the hard palate $(42.8 \%-68.8 \%)$ is reported to be the most commonly affected area, followed by the upper lip (10.1\%) and cheek (5.5\%). ${ }^{(3-5)}$

Around $50 \%$ of tumours of the minor salivary gland are malignant in nature. ${ }^{(1,2)}$ They occur more frequently in women than men and in the fourth to sixth decade of life.(1)

${ }^{1}$ Department of Otorhinolaryngology and Head-Neck Services, Seth Gordhandas Sunderdas Medical College and King Edward Memorial Hospital, Mumbai, India Correspondence: Dr Shraddha Deshmukh, Resident, Department of Otorhinolaryngology and Head-Neck Services, Seth Gordhandas Sunderdas Medical College and King Edward Memorial Hospital, Parel, Mumbai 400012, India. drshraddhadeshmukh@yahoo.co.in 
The aetiology of pleomorphic adenoma is still not clearly known. However, pleomorphic adenoma is described to have an epithelial origin, along with clonal chromosome abnormalities with aberrations involving $8 q 12$ and $12 q 15 .{ }^{(6)}$ Pleomorphic adenomas tend to present as painless, slowgrowing, submucosal swellings that do not cause fixation or ulceration of the overlying mucosa. ${ }^{(7)}$ The clinical features suggestive of malignant change are sudden increase in size, pain, involvement of skin and deeper layers, and neck adenopathies. On histology, pleomorphic adenomas are complex lesions that consist of both epithelial and myoepithelial components, with varied patterns of arrangement and embedded in a mucopolysaccharide stroma. They tend to have an encapsulated appearance; however, this is due to compression of the surrounding salivary parenchyma and fibrosis, which results in a pseudocapsule. ${ }^{(8)}$ The treatment of choice is wide local excision with adequate margins, followed by final histopathology to establish the diagnosis. Due to microscopic interruptions in the pseudocapsule, incomplete excisions or rupture of the capsule during excision can lead to local recurrence. ${ }^{(8)}$ Regular follow-up is warranted in patients with minor salivary gland tumours due to the malignant potential of these tumours and the increased tendency of local recurrences.

\section{REFERENCES}

1. Spiro RH. Salivary neoplasms: overview of a 35-year experience with 2,807 patients. Head Neck Surg 1986; 8:177-84.

2. Eveson JW, Cawson RA. Salivary gland tumours. A review of 2410 cases with particular reference to histological types, site, age and sex distribution. J Pathol 1985; 146:51-8.

3. van Heerden WF, Raubenheimer EJ. Intraoral salivary gland neoplasms: a retrospective study of seventy cases in an African population. Oral Surg Oral Med Oral Pathol 1991; 71:579-82.

4. Wang D, Li Y, He H, et al. Intraoral minor salivary gland tumors in a Chinese population: a retrospective study on 737 cases. Oral Surg Oral Med Oral Pathol Oral Radiol Endod 2007; 104:94-100.

5. Toida M, Shimokawa K, Makita H, et al. Intraoral minor salivary gland tumors: a clinicopathological study of 82 cases. Int J Oral Maxillofac Surg 2005; 34:528-32.

6. Farina A, Pelucchi S, Grandi E, Carinci F. Histological subtypes of pleomorphic adenoma and age-frequency distribution. Br J Oral Maxillofac Surg 1999; 37:154-5.

7. Heeneman H. Parapharyngeal space tumours. In: Kerr AG, ed. Scott Brown's Otolaryngology. 5th ed. London: Butterworth \& Co Ltd, 1987: 380-91.

8. Jorge J, Pires FR, Alves FA, et al. Juvenile intraoral pleomorphic adenoma: report of five cases and review of the literature. Int J Oral Maxillofac Surg 2002; 31:273-5. 